\title{
Law and the Public's Health
}

One of the major challenges in population health and health-care quality is assuring access to specialized services for medically underserved populations. Of particular concern are populations at significantly elevated risk for health disparities, for whom the research shows increased barriers to specialized, medically necessary care. This installment of Law and the Public's Health examines the current state of law regulating telemedicine and how the law might be used to ease barriers to the use of telemedicine to improve health-care access.

Sara Rosenbaum, JD

The George Washington University School of Public Health and Health Services

Department of Health Policy, Washington, DC

\section{MEDICARE PAYMENT RULES AND TELEMEDICINE}

Katie Horton, JD, MPH, RN

Mary-Beth Malcarney, JD, MPH

NaOmi Seiler, JD

Telemedicine offers the opportunity to expand key clinical, preventive, and supportive health services to populations facing structural barriers to health improvement, such as poverty, rural settings, or lack of nearby specialists. Telemedicine is especially important for Medicare patients experiencing an acute event such as a stroke, where specialized expertise is often required to facilitate delivery of the most advanced therapies. This installment of Law and the Public's Health reviews current Medicare law related to telemedicine reimbursement, comparing these Medicare policies with those used by other payers, and describing options for Medicare payment reforms that would improve beneficiary access to telemedicine services.

\section{TELEMEDICINE AND MEDICARE REIMBURSEMENT}

Telemedicine is the use of electronic information and communication methods to provide direct patient care, generally when the patient and attending physician are not located at the same facility. ${ }^{1}$ For individuals experiencing acute emergencies that trigger the need for rapid diagnosis and specialized care, telemedicine services may be highly valuable, especially where hospitals lack specially trained providers. ${ }^{2}$ In the case of stroke, for example, most hospitals do not have neurologists and other stroke specialists on staff; as a result, fewer than $5 \%$ of eligible patients receive the most effective, life-saving treatment, known as intravenous tissue plasminogen activator (tPA). ${ }^{3}$ Telemedicine technologies for the delivery of stroke care-known as telestroke services-have been shown to help mitigate the effects of specialist shortages by enhancing timely stroke diagnosis, increasing administration of tPA, and improving long-term outcomes. ${ }^{4,5}$

Currently, Medicare Part B, which covers physician services, pays for telemedicine services. ${ }^{6}$ However, federal law allows payment for telemedicine only when patients present at an originating site, defined as a site that is (1) located in a designated rural health professional shortage area, (2) located in a county that is not included in a metropolitan statistical area, or (3) participating in a Federal Telemedicine Demonstration Project. ${ }^{7}$ Other facilities, such as urban hospitals with limited on-call specialty capabilities in their emergency departments or community health centers located in urban medically underserved neighborhoods, cannot qualify as originating sites. While these sites may render care to patients in need, they do not qualify for Medicare payment for enhanced patient access to telemedicine services even where telemedicine services would assist patients with acute care needs. Medicare's restrictive payment policy limits the utility of telemedicine in non-rural health-care settings in which beneficiaries experience documented and structural barriers to care, such as specialist shortages.

Medicare's managed care option, Medicare Advantage (MA), provides some flexibility that enables plans to modify Medicare's basic payment rules. Overall, the majority of MA plans adhere to the standard Medicare originating site rule. ${ }^{8-11}$ While one MA plan maintains a payment policy that allows for telestroke reimbursement in non-rural areas, ${ }^{12} \mathrm{MA}$ plans generally appear to adhere to traditional Medicare payment principles concerning telemedicine. 


\section{TELEMEDICINE REIMBURSEMENT BY OTHER PAYERS}

Telemedicine is becoming increasingly widespread, particularly with payers other than Medicare, partially because of policy changes, physician shortages, and technological advances. A number of payers appear to be offering broader coverage and better reimbursement for telemedicine services than Medicare.

\section{Medicaid}

States have the flexibility to incorporate telemedicine services into their Medicaid programs. While states vary, many Medicaid programs, perhaps reflecting the documented problem of limited access to specialty care, ${ }^{13}$ provide more comprehensive coverage of telemedicine services than Medicare. As of January 2013, 42 states provided some Medicaid coverage for telemedicine. ${ }^{14}$ Some states allow Medicaid telemedicine coverage only in rural areas, ${ }^{15}$ while others specifically tie Medicaid telemedicine reimbursement to permissible reimbursement under Medicare. ${ }^{16,17}$ Still other states will pay for telemedicine services in non-rural areas. For example, California's Telemedicine Reimbursement Handbook states, "Unlike Medicare, there is no specific requirement under Medi-Cal that the Telemedicine service be provided in a rural or rural underserved area." 18

State Medicaid programs also establish provider qualification standards for purposes of telemedicine payment. In Alabama, for example, providers in any setting can provide telemedicine services to patients originating from any facility, but they must be explicitly recognized for payment purposes as telemedicine providers within their specialty type.$^{19}$ Other Medicaid programs allow reimbursement only for certain beneficiaries (e.g., telemedicine in Florida is available only to Medicaid-enrolled children),${ }^{14}$ or only offer reimbursement when telemedicine services are provided in relation to specific diagnoses (e.g., Kansas limits telemedicine to office visits, individual psychotherapy, and pharmacological management).$^{20}$ Finally, while some state Medicaid payment policies appear to cover telemedicine furnished in any health-care setting, including out-of-state settings, ${ }^{21}$ other states place strict limitations on eligible settings. For example, Arkansas only covers telemedicine services provided by federally qualified health centers ${ }^{14}$ while Indiana's Medicaid program will only reimburse for telemedicine services when sites are more than 20 miles apart. ${ }^{22}$

\section{Veterans Health Administration (VHA) and TRICARE}

The VHA currently operates the world's largest telehealth program, serving more than 50,000 veterans in 2011. ${ }^{23}$ Patients enrolled in the VHA program, most of whom have chronic conditions such as heart failure, hypertension, diabetes, or posttraumatic stress disorder, receive free telemonitoring equipment and services from care coordinators who teach them selfmanagement. The VHA has worked to expand access to telehealth, implementing a 2012 change in policy to eliminate copays for most telehealth services, ${ }^{24}$ and does not set any rural requirement. The VHA model has proven so successful that researchers in the United Kingdom are urging the country's National Health Service to model its planned telehealth program after the VHA. ${ }^{25}$

Telemedicine is also a TRICARE benefit. A telehealth policy set by the U.S. Department of Defense in 2003 does not limit the provision of telehealth services only to rural areas, ${ }^{26}$ and a subsequent telehealth guidebook issued in June 2011 does not appear to set any originating site restrictions. ${ }^{27}$

\section{Private insurance}

Coverage of telemedicine among private insurers has increased in recent years as a result of state legislative mandates, although these state laws would not apply to self-insured employer-sponsored plans, which currently cover more than half of all workers in the U.S. In 2012 alone, five states passed telemedicine coverage mandates, and, as of January 2013, 16 states required private insurance plans to cover telemedicine services. ${ }^{14}$ Most of these policies encourage telemedicine coverage in non-rural areas. For example, Maryland law prohibits insurers from distinguishing between rural and urban patients in setting telemedicine payment policies. ${ }^{28}$

Even where states do not mandate telemedicine coverage, a number of private insurers are offering access to telemedicine in non-rural areas, indicating that insurers nationwide may be seeing the value of providing telemedicine to patients in urban and suburban settings. ${ }^{29,30}$

\section{INNOVATION CENTER DEMONSTRATIONS: A STEP TOWARD WIDER TELEMEDICINE REIMBURSEMENT UNDER MEDICARE}

Medicare has been slow to recognize the importance of telemedicine services. However, the Centers for Medicare \& Medicaid Services (CMS) is taking a step in the right direction by testing more flexible telemedicine programs as part of demonstration projects funded by the CMS Innovation Center established under the Affordable Care Act. ${ }^{31}$ In the spring of 2012, the Innovation Center announced several Healthcare Innovation Awards that focus on innovative telemedicine programs 
for Medicare- and Medicaid-eligible populations. Four of these Innovation Center projects are aimed at increasing telemedicine for patients in urban settings. ${ }^{32}$

While the interest in testing telemedicine programs in urban settings is promising, only successful Innovation Center projects-that is, those that improve the quality of care and/or show a positive return on investment-qualify for expansion by the Secretary of the U.S. Department of Health and Human Services on a regional or national basis. Positive outcomes in any of these telemedicine projects may sway policy makers to encourage broader use of telemedicine in non-rural settings.

\section{IMPLICATIONS FOR PUBLIC HEALTH PRACTICE AND POLICY}

A looming increase in the number of Medicare beneficiaries will create an unprecedented demand for finding more efficient ways to deliver medical care needed for the treatment and management of chronic health conditions that impair health. Telemedicine may offer such an approach, thereby helping to extend the life of the Medicare Trust fund, projected in 2013 to last until 2026. As the Medicare population continues to grow-from nearly 51 million in 2012 to a projected 81 million in 2030-expanded use of telemedicine in Medicare may offer a solution to the urgent need to improve the quality and efficiency of care purchased by the program. ${ }^{33}$

In the 112th Congress, legislators introduced bills aimed at removing Medicare's rural originating site restriction. The Telehealth Promotion Act of 2012, ${ }^{34}$ introduced by Representative Mike Thompson (D-CA), included a provision that would remove the current originating site restriction. The measure has not yet been reintroduced in the 113th Congress, but if eventually passed, the Telehealth Promotion Act could enhance access to telehealth services for Medicare patients in non-rural areas. Given Medicare's systemwide influence on health-care payment policies, using the various legal tools available for federal policy-making-including legislative amendments, the expansion of CMS' demonstration authority, incentivizing MA contractors to use broader telemedicine coverage, and payment policies-all would appear to be critical in moving the health system more broadly in the direction of greater efficiency through telemedicine at a crucial time in Medicare policy development. While additional research examining the impact of telemedicine on costs and health outcomes would be highly beneficial, the evidence to date suggests the positive effects of telemedicine on health-care organization and delivery.

Katie Horton is a Research Professor, Mary-Beth Malcarney is an Assistant Research Professor, and Naomi Seiler is an Associate Research Professor, all in the Department of Health Policy at The George Washington University School of Public Health and Health Services in Washington, D.C.

Address correspondence to: Katie Horton, RN, MPH, JD, The George Washington University School of Public Health and Health Services, Department of Health Policy, 2021 K St. NW, Ste. 800, Washington, DC 20006; tel. 202-994-4219; email <khorton@ gwu.edu>.

C2014 Association of Schools and Programs of Public Health

\section{REFERENCES}

1. Institute of Medicine. The role of telehealth in an evolving health care environment-workshop summary. Washington: National Academies Press; 2012.

2. LaMonte MP, Bahouth MN, Hu P, Pathan MY, Yarbrough KL, Gunawardane R, et al. Telemedicine for acute stroke: triumphs and pitfalls. Stroke 2003;34:725-8.

3. Adeoye O, Hornung R, Khatri P, Kleindorfer D. Recombinant tissue-type plasminogen activator use for ischemic stroke in the United States: a doubling of treatment rates over the course of 5 years. Stroke 2011;42:1952-5.

4. Switzer JA, Demaerschalk BM, Xie J, Fan L, Villa KF, Wu EQ. Costeffectiveness of hub-and-spoke telestroke networks for the management of acute ischemic stroke from the hospitals' perspectives. Circ Cardiovasc Qual Outcomes 2013;6:18-26.

5. Schwamm LH, Holloway RG, Amarenco P, Audebert HJ, Bakas $\mathrm{T}$, Chumbler NR, et al. A review of the evidence for the use of telemedicine within stroke systems of care: a scientific statement from the American Heart Association/American Stroke Association. Stroke 2009;40:2616-34.

6. 42 U.S.C. $\$ 1395 \mathrm{j}-\mathrm{w}-5$.

7. 42 U.S.C. $\$ 1395 \mathrm{~m}(\mathrm{~m})(4)(\mathrm{C})$.

8. UnitedHealthcare. Coverage summary: telemedicine/telehealth services, UnitedHealthcare Medicare Advantage plans [cited 2013 Nov 19]. Available from: URL: https://www.unitedhealthcareonline.com/ccmcontent/ProviderII/UHC/en-US/Assets/ProviderStaticFiles/ProviderStaticFilesPdf/Tools\%20and\%20Resources/ Policies \% 20and\%20Protocols/UnitedHealthcare $\%$ 20Medicare $\% 20$ Coverage/Telehealth and Telemedicine_SH_Ovations.pdf

9. UnitedHealthcare. 2013 evidence of coverage: UnitedHealthcare Group Medicare Advantage (PPO), group name (plan sponsor): County of Henrico-Schools group number: 68145 [cited 2013 Nov 19]. Available from: URL: http://www.co.henrico.va.us/hr/ benefits/retire/retire_uhc_eoc_ppo.pdf

10. Aetna. 2013 evidence of coverage for Aetna Medicare PPO. 2013 Jan 1 [cited 2013 Nov 19]. Available from: URL: https://www.strsoh. org/pdfs/AetnaEOC13B.pdf

11. Anthem Blue Cross Life and Health. University of California: high option supplement to Medicare: summary plan description. 2010 [cited 2013 Nov 19]. Available from: URL: http://www.anthem.com $/ \mathrm{ca} /$ member $/ \mathrm{f0} / \mathrm{s} 0 / \mathrm{t} 0 / \mathrm{pw} \_b 138483$.pdf?refer=group\&name $=\mathrm{uc}$

12. Highmark. Highmark Medicare advantage medical policy in West Virginia. 2011 Aug 8 [cited 2013 Nov 19]. Available from: URL: https://www.highmarkbcbswv.com/medadvpolicy /printerfriendly/Z-68-005.html

13. Medicaid and CHIP Payment and Access Commission (US). Report to the Congress on Medicaid and CHIP. Washington: MACPAC; March 2011.

14. National Conference of State Legislatures. State coverage for telehealth services. January 2013 [cited 2013 Nov 19]. Available from: URL: http://www.ncsl.org/issues-research/health/state-coveragefor-telehealth-services.aspx 
15. Texas Health and Human Services Commission. Telemedicine medical services in Texas Medicaid: biennial report to the Texas Legislature. Austin (TX): Texas Health and Human Services Commission; December 2010. Also available from: URL: http://www hhsc.state.tx.us/reports/2010/Telemedicine-Medical-Services-0910 .pdf [cited 2013 Nov 19].

16. State of West Virginia Department of Health and Human Resources. Chapter 519 covered services, limitations, and exclusions for practitioner services, including physicians, physician assistants, and advanced registered nurse practitioners [cited 2013 Nov 19]. Available from: URL: http://www.dhhr.wv.gov/bms/Documents /manuals_Chapter_519_Practitioners.pdf

17. Tex Gv. Code Ann. \$531.02173 (2003).

18. California Telemedicine \& eHealth Center. Telemedicine reimbursement handbook. 2006 [cited 2013 Nov 19]. Available from: URL: http://www.nrtrc.org/wp-content/uploads/TelemedicineReimbursement-Handbook1.pdf

19. Alabama Medicaid Agency. Provider manual. July 2012 [cited 2013 Nov 19]. Available from: URL: http://medicaid.alabama. gov/documents/6.0_Providers/6.7_Manuals/6.7.6_Provider Manual_2012/6.7.6.3_July_2012/6.7.6.3_Jul12_28.pdf

20. Kansas Department of Health and Environment, Division of Health Care Finance. Kansas medical assistance program provider manual. February 2012 [cited 2013 Nov 19]. Available from: URL: https:// www.kmap-state-ks.us/Documents/Content/Provider\%20Manuals /Gen\%20benefits_02242012_12025.pdf

21. Illinois Department of Healthcare and Family Services. Informational notice: expansion of telehealth services. 2010 Jan 12 [cited 2013 Nov 19]. Available from: URL: http://www.hfs.illinois.gov /assets/011210n2.pdf

22. Indiana Health Coverage Programs. Provider bulletin: telemedicine. 2008 Jan 8 [cited 2013 Nov 19]. Available from: URL: http:/ / www .indianamedicaid.com/ihcp/bulletins/bt200802.pdf

23. Veterans Health Administration (US), Office of Telehealth Services. A new era of telehealth expansion. VHA Telehealth Quarterly February 2012;11(1). Also available from: URL: http://www.telehealth .va.gov/newsletter/2012/021312-Newsletter_Vol11Iss01.pdf [cited 2013 Nov 19].
24. 38 C.F.R. Part 17: exempting in-home video telehealth from copayments: direct final rule; confirmation of effective date. Fed Reg 2012;77:58952-3.

25. 2020Health.org. Cruickshank J. Telehealth: what can the NHS learn from experience at the US Veterans Health Administration? London: 2020Health.org; January 2012.

26. TriCare policy manual 6010.54-M: telemental health (TMH)/telemedicine. 2003 Apr 17 [cited 2013 Nov 19]. Available from: URL: http:/ / www.humana-military.com/southmanuals/policy/AsOf C7S22_1.pdf

27. National Center for Telehealth \& Technology (T2) Defense Centers of Excellence for Psychological Health \& TBI. DoD telemental health guidebook. 2011 Jun 9 [cited 2013 Nov 19]. Available from: URL: http://t2health.org/sites/default/files/cth/guidebook /tmh-guidebook_06-11.pdf

28. MD Code $\$ 15-139$ (f)

29. BlueCross BlueShield of North Carolina. Corporate medical policy: telemedicine. February 2012 [cited 2013 Nov 19]. Available from: URL: http://www.bcbsnc.com/assets/services/public/pdfs /medicalpolicy/telemedicine.pdf

30. Empire BlueCross BlueShield. Empire BlueCross BlueShield professional reimbursement policy: telemedicine and telehealth services. 2012 Nov 30 [cited 2013 Nov 19]. Available from: URL: http://www.empireblue.com/provider/noapplication/f5/s4/t0 /pw_b157689.pdf

31. Pub. L. No. 111-148, 124 Stat. 119, \$3021 (March 23, 2010)

32. Centers for Medicare \& Medicaid Services (US). Health Care Innovation Award project profiles. 2012 Jul 30 [cited 2013 Nov 19]. Available from: URL: http://innovation.cms.gov/Files/x HCIA-Project-Profiles.pdf

33. Centers for Medicare \& Medicaid Services (US). 2013 annual report of the boards of trustees of the federal hospital insurance and federal supplementary medical insurance trust funds. Communication to Honorable John A. Boehner, Speaker of the House of Representatives, and Honorable Joseph R. Biden, Jr., President of the Senate. 2013 May 31 [cited 2013 Nov 19]. Available from: URL: http://downloads.cms.gov/files/TR2013.pdf

34. H.R. 6719, 112th Congress (2012). 